and only those under 16 would remain non-sensitized; to replace the hypersensitive 16 to 29 age group by non-sensitive individuals would take 14 to 16 years. If hypersensitivity conferred a slight resistance to infestation or a lesser degree of contagion a gap of about 15 years might be expected between the end of one and the beginning of the next epidemic. Accurate data for past epidemics are not available, but Gray (1941) quotes the number of children treated for scabies at L.C.C. cleansing stations from 1919 to 1938, from which it is clear that the first world war epidemic declined rapidly in 1920, numbers remained low until 1930, when a slow rise began, and there was a precipitous rise in 1937. Hellier (1939), in Leeds, dates the rise in his practice from 1933. The gap here is from 10 to 14 years. The epidemic of the 1930's continued through the second world war and declined sharply in 1949 (Epstein, 1955). The rise reported in this paper thus started 15 years later and so further supports our hypothesis involving "herd resistance."

The case histories are a vivid reminder of the need for vigilance and for revision of diagnosis when supposedly effective therapy fails. The tendency in dermatological therapy to prescribe potent remedies, including systemic corticosteroids, before making a definitive diagnosis is to be deplored. In the case of scabies such a policy is imprudent and possibly dangerous, and leads to needless waste of medication, vain effort by the patient, waste of time of medical personnel, and increased cost to the taxpayer.

\section{Summary}

A continuing rise in the past three years in the incidence of scabies at St. John's Hospital for Diseases of the Skin, London, from an average of $0.9 \%$ of all new patients to $2.4 \%$ is reported. It is suggested that this heralds another epidemic.

From an analysis of the case notes and a review of past epidemics, the hypothesis that epidemics are directly related to " herd hypersensitivity" to scabies is presented ; it accounts for the gap of about 15 years between the end of one and the start of the next epidemic.

Thanks are due to the physicians at St. John's Hospital for Diseases of the Skin and to Dr. Ambrose King, of the Whitechapel Clinic, for permitting access to case notes, and to Dr. King and Dr. F. R. Bettley for advice on preparing this paper.

REPERENCES

Annual Report of the Chief Medical Officer for England and Wales (1952-1965). H.M.S.O., London.

Epstein, E. (1955). Arch. Derm., 71, 192

Gray, A. M. H. (1941). Brit. F. Derm., 53, 148

Heilesen, B. (1946). Acta derm.-venereol. (Stockh.), Suppl. No. 14.

Hellier, F. F. (1939). Trans. St. Fohn's Hosp. derm. Soc. (Lond.), 28, 52. Mellanby, K. (1943). Scabies. Oxford War Manuals. London.

\title{
Prescribing of Chloramphenicol in General Practice
}

\author{
T. W. MEADE,* B.M., M.R.C.P.
}

A study of prescribing by general practitioners revealed very wide individual differences for which no satisfactory explanations have so far been found (Lee, 1964 ; Weatherall, 1964 ; Draper, 1964 ; Lee, Draper, and Weatherall, 1965 ; Joyce, Last, and Weatherall, 1967). It is possible that such differences in prescribing are related to skill, training, or other aspects of the quality of general practice. Any attempt to measure these attributes must, if it is to be meaningful, employ an acceptable index; the prescribing of chloramphenicol may provide one. The present study was carried out at a time when the limited therapeutic usefulness and the dangers of this drug had been much publicized and were widely recognized (Wilson, 1956; Shaw and McLean, 1957 ; Registrar General, 1960 ; Brit. med. f., 1960, 1961). One of the annotations in the British Medical fournal just cited appeared at the beginning of the month in which the main part of the present study was carried out. It said: "The occurrence of aplastic anaemia ... is so dangerous . . . that many physicians feel it wise to avoid using the drug [chloramphenicol] systemically when any alternative effective therapy is available." In fact, since the first British cases of fatal aplastic anaemia due to chloramphenicol were described (Hawkins and Lederer, 1952; Wolman, 1952) frequent reports and warnings of toxicity have appeared in the literature. Moreover, it is generally agreed that in only comparatively few cases is there no effective alternative to chloramphenicol.

The hypothesis now to be tested is that prescribing of chloramphenicol, for the reasons just indicated, is related to definable characteristics of general practitioners, such as their skill and training.

- Medical Research Council's Social Medicine Research Unit, the London Hospital, London E.1.

\begin{abstract}
Method
Chloramphenicol Prescribing

The prescriptions for chloramphenicol in this study were all for capsules or mixture (palmitate)-that is, preparations for systemic use. Prescriptions containing chloramphenicol for topical use-as in ear and eye drops, eye ointment, and cream -are not considered. The prescriptions analysed were those written by all the general practitioners in several English towns in March or May 1961, but only doctors with (a) 500 or more patients on their lists who $(b)$ issued a total of at least 250 prescriptions during the study month are considered. There were 285 doctors, responsible for 532,000 patients; and they issued 250,000 prescriptions in all during the study period. Of the 285 doctors 182 satisfied criteria $(a)$ and $(b)$. Of the 182 $149(82 \%)$ issued at least one prescription for chloramphenicol during the study month. A total of 1,547 prescriptions for chloramphenicol were issued during this period; this gives a rate of 8.5 prescriptions per doctor per month. Taking the total volume of chloramphenicol used in relation to the popuiation served by the doctors, nearly three prescriptions were issued for every 1,000 patients during the study period. About two-thirds of the prescriptions were issued for courses of 5 to 10 days. Of the remaining one-third most were issued for courses lasting 10 days or more. (A few more were so written that it was not possible to determine the intended duration of the course.) Wade (1966), in a survey of 756 general practitioners in Northern Ireland responsible for $1,411,000$ patients, found that 3,123 prescriptions for chloramphenicol were issued during December 1962. This gives a rate of 4.1 prescriptions per doctor for the month and a rate of 2.2 prescriptions per 1,000 patients, figures which are rather lower than in the present study, though of the same order.
\end{abstract}




\section{Indices of Performance}

Three indices of performance were available to classify the doctors.

Educational Index.-Each doctor was classified on the type of his primary medical qualifications: three points for a university qualification, two for a Conjoint Board qualification alone, and one for apothecary's qualification alone, and on further medical qualifications (different weightings being given to different qualifications-for example, an M.R.C.P. or F.R.C.S. was allotted more points than a postgraduate diploma). The doctors were also classified on length and type of postqualification hospital experience (medical or paediatric experience, for example, being rated more than pathology). The scale had a theoretical maximum of 16 . The mean was 6.9 points, the lowest score 2, and the highest 14 .

Consultant Index.-Half the 182 doctors were classified by panels of local National Health Service consultants on a scale of 11 points-five points for general knowledge in medicine, three for general care and concern for patients, and three for attendance at extramural activities. The mean was 6.0 points, the lowest score 3, and the highest 11 .

Personal Interview Index.-Half the doctors were interviewed personally by Dr. J. M. Last (Joyce et al., 1967). The interview schedules were then read by four workers (two medical and two non-medical), and from the doctors' answers to 16 items each reader gave a score based on an overall impression of the performance of the doctor. These items included details of medical education; practice organization; views on prescribing; views on role of general practice; and extramural medical interests. The four scores for each general practitioner were averaged, and this figure was used as the index. The mean was 12.4 points, the lowest score 6.5 , and the highest 17 .

Correlations between these three indices range from +0.45 , between the personal interview index and the consultant index, to +0.39 , between the consultant index and educational index; they are all highly significant. Thus 15 to $20 \%$ of the variance between any two of the indices is due to common factors, while the remaining 80 to $85 \%$ is probably an indication that they are measuring different factors. It is therefore reasonable to assume that, though the indices are not independent, to an appreciable extent they do measure different aspects of general practice.

In terms of the hypothesis already advanced, it was postulated that the doctors with the highest number of points on these three scales would be the ones who prescribed least chloramphenicol.

In the Tables that follow the ranges of the indices and of the chloramphenicol prescribing rates have been divided so far as possible into three, to include about the same number of doctors in the high, medium, and low thirds on each scale. All the indices were roughly normally distributed.

\section{Results}

Table I shows the distribution of chloramphenicol prescribing rates.

TABLE I.-Prescribing of Chloramphenicol by 182 General Practitioners. \begin{tabular}{c|c|c|c}
\multicolumn{3}{c}{ Rate Per 1,000 Patients on Their Lists } \\
\hline $\begin{array}{c}\text { Rate per 1,000 } \\
\text { Patients }\end{array}$ & $\begin{array}{c}\text { No. of General } \\
\text { Practitioners }\end{array}$ & $\begin{array}{c}\text { Rate per 1,000 } \\
\text { Patients }\end{array}$ & $\begin{array}{c}\text { No. of General } \\
\text { Practitioners }\end{array}$ \\
\hline 0.0 & 33 & $5 \cdot 0-$ & 4 \\
$0.1-$ & 15 & $6 \cdot 0-$ & 9 \\
$0.5-$ & 26 & $7 \cdot 0-$ & 2 \\
$1.0-$ & 26 & $9 \cdot 0-$ & 4 \\
$2.0-$ & 20 & $10 \cdot 0-$ & 8 \\
$3 \cdot 0-$ & 19 & $20 \cdot 0-38 \cdot 0$ & 4 \\
$4 \cdot 0-$ & 9 & & 4 \\
\hline
\end{tabular}

Average: 2.91 per 1,000 patients.
Total number of general practitioners, 182 .
Table II shows how the high, medium, and low chloramphenicol prescribers were distributed according to the educational index. There is a more or less random distribution of prescribing within the three divisions of the doctors; the initial hypothesis is not supported in any way.

TABLE II.-Educational Index (Points Gained) v. Chloramphenicol Prescribing (Rates per 1,000 Patients on List) for 182 General Practitioners in Several Towns

\begin{tabular}{c|c|c|c|c|c} 
& & \multicolumn{3}{|c}{ Educational Index } \\
\hline $\begin{array}{c}\text { Chloramphenicol prescribing rates } \\
\text { per 1,000 patients }\end{array}$ & & $2-5$ & $6-7$ & $8-14$ & Total \\
\hline $0-0.4$ & 13 & 17 & 18 & 48 \\
$0 \cdot 5-2 \cdot 9$ & 21 & 20 & 30 & 71 \\
$3 \cdot 0-38 \cdot 0$ & 15 & 21 & 27 & 63 \\
\hline Total & 49 & 58 & 75 & $182^{*}$
\end{tabular}

Lowest score $=2$. Highest score $=14 . x^{2}=1 \cdot 17$. D.F. $=4$. $0-9>$ P $>0.8$.

Lowest score $=2$. Highest score $=14 . \chi^{2}=1 \cdot 17$.
- See text for explanation of totals in Tables II $-V$.

Table III shows a random distribution of prescribing rates within the consultant index.

TABLE III.-Consultant Index (Points Gained) v. Chloramphenicol Prescribing (Rates per 1,000 Patients on List) for Half These General Practitioners

\begin{tabular}{|c|c|c|c|c|c|}
\hline & & \multicolumn{4}{|c|}{ Consultane Index } \\
\hline & & $3-4$ & $5-6$ & $7-11$ & Total \\
\hline \multirow[t]{2}{*}{$\begin{array}{l}\text { Chloramphenicol prescribing rates per } \\
1,000 \text { patients }\end{array}$} & $\begin{array}{l}0-0.4 \\
0.5-2.9 \\
3.0-38.0\end{array}$ & $\begin{array}{l}9 \\
6 \\
6\end{array}$ & $\begin{array}{r}11 \\
14 \\
8\end{array}$ & $\begin{array}{l}11 \\
17 \\
11\end{array}$ & $\begin{array}{l}31 \\
37 \\
25\end{array}$ \\
\hline & Total & 21 & 33 & 39 & 93 \\
\hline
\end{tabular}

Lowest score $=3$. Highest score $=11 . \quad \chi^{2}=1.88 . \quad$ D.F. $=4 . \quad 0 \cdot 8>\mathbf{P}>0.7$.

Table IV shows the results for the 91 doctors for whom the personal interview index was used. Again the distribution lends no support to the hypothesis that doctors scoring high on these performance scales would be low prescribers of chloramphenicol.

TABLE IV.-Personal Interview Index (Points Gained) v. Chloramphenicol Prescribing (Rates per 1,000 Patients on List) for Half These General Practitioners

\begin{tabular}{c|c|c|c|c|c} 
& & \multicolumn{3}{|c|}{ Personal Interview Index } \\
\hline $\begin{array}{c}\text { Chloramphenicol prescrib- } \\
\text { ing rates per 1,000 } \\
\text { patients }\end{array}$ & & $6 \cdot 5-11 \cdot 5$ & $12-13$ & $13 \cdot 5-17$ & Total \\
\hline $\begin{array}{c}0-0 \cdot 4 \\
0 \cdot 5-2 \cdot 9\end{array}$ & 10 & 10 & 4 & 24 \\
$3 \cdot 0-38 \cdot 0$ & 6 & 16 & 12 & 37 \\
\hline Total & 25 & 39 & 27 & 91 \\
\hline
\end{tabular}

Lowest score $=6 \cdot 5$. Highest score $=17 \cdot 0 . x^{2}=4 \cdot 47$. D.F. $=4.0 \cdot 3>$ P $>0 \cdot 2$.

Combining the scores for the 44 doctors who happened to be classified by all three indices gave totals which were also randomly distributed within the high, medium, and low chloramphenicol prescribing rates.

Table $\mathrm{V}$ shows features about $(a)$ the 33 doctors of the total 182 who issued no prescriptions for chloramphenicol, and $(b)$ the 34 doctors of the total 182 who issued five or more prescriptions for it-that is, the lowest and highest prescribers. The 34 high prescribers (19\% of the 182 doctors) issued 906 (59\%) of the 1,547 prescriptions for chloramphenicol, giving an average of 27 prescriptions per doctor, or about one prescription each on each working day. There were more doctors under 40 among the high prescribers, but otherwise there were no important differences in the age structure of the two groups. The age difference shown in Table $\mathrm{V}$ is to be expected from evidence, already discussed, that younger doctors in general tend to prescribe at a higher rate than older ones (Draper, 1964). There are also more women doctors among the high prescribers than among those prescribing none. The high chloramphenicol prescribers clearly are high prescribers of other antibiotics, and overall. It is interesting, moreover, that $59 \%$ of the frequent prescribers issued at least one prescription for a course of more than 10 days' duration, while of the 115 doctors who issued prescriptions for chloramphenicol at a rate of less than $S$ per 
thousand patients only $38 \%$ did so. The two groups are in other important respects typical of all 182 doctors, whose average age, for example, was 45 , and of whom $78 \%$ had primary medical qualifications from a university.

TABLB V.-Characteristics of 34 General Practitioners who Issued Five or More Prescriptions for Chloramphenicol per 1,000 Patients on Their Lists During the Study Month, Compared with 33 General Practitioners Who Issued None

\begin{tabular}{|c|c|c|c|}
\hline & & $\begin{array}{l}\text { No } \\
\text { Prescriptions. } \\
33 \text { General } \\
\text { Practitioners }\end{array}$ & $\begin{array}{c}\text { Five or More } \\
\text { Prescriptions } \\
\text { per } 1,000 \\
\text { Patients. } \\
34 \text { General } \\
\text { Practitioners }\end{array}$ \\
\hline \multirow{3}{*}{\multicolumn{2}{|c|}{ 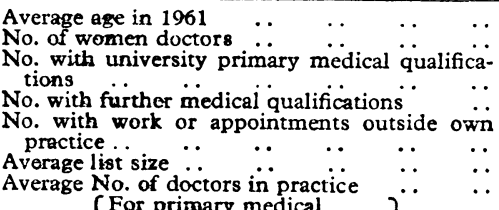 }} & $\begin{array}{c}49 \cdot 8 \\
1\end{array}$ & $\underset{4}{42.1}$ \\
\hline & & & $\begin{array}{r}29 \\
8\end{array}$ \\
\hline & & $\underset{2 \cdot 15}{21}$ & $\begin{array}{c}18 \\
2,649 \\
2 \cdot 6 \bar{j}\end{array}$ \\
\hline \multirow{2}{*}{$\begin{array}{c}\text { Educa- } \\
\text { tionat } \\
\text { index }\end{array}$} & \multirow{2}{*}{$\left.\begin{array}{l}\text { Fualifications } \\
\text { For further qualifications } \\
\text { For length of postgraduate } \\
\text { hospital experience } \\
\text { For type of postgraduate } \\
\text { hospital experience }\end{array}\right\}$} & $\begin{array}{l}2.67 \\
0.33\end{array}$ & $\begin{array}{l}2.74 \\
0.26\end{array}$ \\
\hline & & $2 \cdot 30$ & $2 \cdot 74$ \\
\hline \multirow{3}{*}{\multicolumn{2}{|c|}{$\begin{array}{l}\text { No. of prescriptions for all remedies per } 1,000 \\
\text { patients } \\
\text { p.. of prescriptions for antibiotics per } 1,000 \\
\text { pation be } . . \\
. .\end{array}$}} & 1.33 & 1.79 \\
\hline & & 335 & 429 \\
\hline & & & 22 \\
\hline
\end{tabular}

For defnitions see text.

\section{Discussion}

It was felt that chloramphenicol was a remedy whose disadvantages would have been so well known that it would hardly have been used at all, and that doctors who prescribed very much or very little could be classed according to the kind of indices of performance that have been used. Instead, $82 \%$ of the doctors prescribed chloramphenicol ; and it is disappointing that these indices of doctors' performance have turned out to be such poor "predictors."

Some possible explanations are as follows. Firstly, the indices used are of no value. Though this could well be true of any of them alone, it is more difficult to accept this explanation in the face of three "blind" and largely independent indices based on different facets of education and practice.

Secondly, analysis of a month's prescribing may be insufficient to define a doctor's prescribing patterns and to allow for these patterns being distorted during the month by one or two unusual cases. Moreover, nothing was known about the patients to whom the prescriptions were issued, either their exact numbers or their diagnoses, or to what extent the general practitioners may have been continuing treatment at the request of doctors in hospitals. However, with 182 doctors and the large number of prescriptions for chloramphenicol issued, there is little reason to suppose that these factors could entirely obscure any significant groupings of the doctors. The agestructure of 15 of the practices in the study was known, but there was no association of high or low chloramphenicol prescribing rates with age of patients. Chloramphenicol prescribing rates were very similar in all the towns studied, and in the two months (March and May) during which the prescriptions were issued.

A third possibility relates to aspects of practice organization. Each doctor was assumed to have written all the prescriptions bearing his executive council stamp; no allowance was made for possible use of one doctor's prescription pads by a partner. It is not known how big a problem this is. Nor is it known how individual doctors' nominal list-sizes reflected the number of patients for whom they actually prescribed. Of the 182 doctors 144 were in partnerships of two or more, and it is likely that many of them prescribed for patients who were nominally not on their lists. This may be a source of error in calculating rates.

These "technical" possibilities apart, the question must be raised that many of the doctors were unaware of the possible hazards of chloramphenicol, or that they felt that aplastic anaemia is so rare and unlikely-with the small doses that were probably given for any individual patient-that the risk taken was justified. Some of the 34 doctors who prescribed chloramphenicol frequently may have done so under careful laboratory monitoring of the white cell count, and for cases (such as chronic chest conditions) where bacterial sensitivities had been determined and chloramphenicol found to be the only suitable antibiotic. This is not known, but of all the remedies which affect the bone marrow chloramphenicol is among the most dangerous, and, as pointed out earlier, it has had much adverse publicity. In such a context the findings are unexpected.

It is unlikely that these possible reasons are sufficient to explain the random distribution of chloramphenicol prescribing within the three indices, and it must be concluded that the use of this particular remedy does not differ from the widely divergent overall prescribing patterns that have been consistently found in this study but which remain unexplained. As has been pointed out elsewhere (Draper, 1964 ; Morris, 1964, 1965), this lack of definable patterns or norms is not confined to prescribing. It is also found in other aspects of the general practitioner's work-for example, in the use made by the doctors of local authority and hospital services. There is an inescapable impression that the work of general practitioners is influenced to a very limited extent by any underlying common approaches. The delay in reporting the present study has been due in large part to repeated but hitherto unsuccessful efforts to find meaningful patterns of prescribing that could be interpreted in terms of obvious parameters of general practitioners and of their work.

\section{Summary}

It is postulated that chloramphenicol prescribing in 1961 would be related to skill, training, and other aspects of performance in general practice.

A sample of general practitioners in several English towns, numbering 182 , were included in the present study.

Of the 182 doctors $149(82 \%)$ issued 1,547 prescriptions for chloramphenicol during a month-an overall rate of 8.5 prescriptions per doctor and of 3 prescriptions per 1,000 patients.

Three separate indices, classifying the 182 doctors according to the differences in their education, their experience after qualification, and various aspects of the quality of performance, have been constructed.

None of the three indices, when tabulated against rates of chloramphenicol prescribing, succeed in dividing the doctors into groupings compatible with the original hypothesis that doctors with high scores would be low prescribers of chloramphenicol.

Possible explanations may lie in the inadequacy of the indices, in substantial differences among the patients in the practices concerned, and in the degree of accuracy in identifying each doctor's prescriptions. On the other hand, these findings may reflect a widespread underestimate of the danger of chloramphenicol by the doctors concerned.

The apparently. random prescribing of chloramphenicol in relation to the indices used is a further example of the lack of definable patterns found in this study of general practitioners and their work.

I wish to thank my colleagues in the Social Medicine Research Unit of the Medical Research Council and in the Department of 
Pharmacology, the London Hospital, for their help and advice with this study. I am especially grateful to Professor J. N. Morris, Director of the M.R.C. Social Medicine Research Unit, and to Professor M. Weatherall, Dr. J. A. Heady, Dr. C. R. B. Joyce, Dr. J. A. H. Lee, Dr. P. A. Draper, Dr. M. J. R. Healy, and Dr. J. M. Last.

Several consultants in the National Health Service, the Joint Pricing Committee for England, and the local executive councils have made invaluable contributions. In the data-processing generous help has been received from the Ministry of Defence, Her Majesty's Stationery Office, and the United Kingdom Atomic Energy Authority, Aldermaston. I am also grateful to IBM United Kingdom Limited for support under their Endowed Research Scheme.
Brit. med. 7., 1960, 2, 1373

REFERENCES

1961, 1, 650, 1019 .

Draper, P. A. (1964). Proc. roy. Soc. Med., 57, 1045.

Hawkins, L. A., and Lederer, H. (1952). Brit. med 7. 2, 423.

Joyce, C. R. B., Last, J .M., and Weatherall, M. (1967). In press. Lee, J. A. H. (1964). Proc. roy. Soc. Med., 57, 1041. Draper, P. A., and Weatherall, M. (1965). Millbank mem. Pd Quart., 43, No. 2, Part 2, p. 285.

Morris, J. N. (1964). Uses of Epidemiology, 2nd ed. Edinburgh (1965). The Times, 8 April.

Registrar General (1960). Statistical Review of England and Wales for 1958, Part III, Commentary. H.M.S.O., London.

Shaw, R. G., and McLean, J. A. (1957). Med. 7. Aust., 1, 352.

Wade, O. L. (1966). 7. Coll. gen. Practit.. 12, 277.

Weatherall, M. (1964). Proc. roy. Soc. Med., 57, 1043.

Wilson, C. (1956). Practitioner, 176, 14.

Wolman, B. (1952). Brit. med. \%., 2, 426.

\title{
Abnormal Haemoglobins in Iran. Observation of a New Variant- Haemoglobin J Iran $\left(\alpha_{2} \beta_{2} 77\right.$ His $\rightarrow$ Asp $)$
}

\author{
S. RAHBAR,* M.D.; D. BEALE, $†$ B.SC. ; W. A. ISAACS, † M.A., B.M., M.R.C.S. \\ H. LEHMANN, $\dagger$ M.D., SC.D., F.R.C.P., F.R.I.C., F.C.PATH.
}

Brit. med.F., 1967, 1, 674-677

We have recently carried out three surveys for abnormal haemoglobins in Iran. Two of them were made in 1964 and in 1965, respectively, at the University Hospital in Shiraz. On both occasions 100 hospital patients coming from Shiraz and near-by areas were investigated, none of whom suffered from haemolytic anaemia. On examination of their haemoglobins for signs of thalassaemia and for abnormal haemoglobins two cases of haemoglobin $A+D$ were found, and in both the $D$ variant was identified by the "fingerprint" technique as haemoglobin D Punjab.

A third survey was carried out in Teheran of 400 consecutive patients presenting with anaemia. Of these, 70 were shown to have thalassaemia, three sickle-cell thalassaemia, 17 the sicklecell trait, one sickle-cell haemoglobin $\mathrm{D}$ disease, and one haemoglobin $\mathrm{C}$ disease. In one patient a fast-moving haemoglobin was discovered. All the patients showing sickling came originally from the south coast of the Caspian Sea, but the fastmoving haemoglobin was found in a man of Central Iranian stock.

\section{Haemoglobin J Iran}

The fast-moving haemoglobin had the electrophoretic mobility of haemoglobin $\mathrm{J}$-that is, on paper electrophoresis at $\mathrm{pH} 8.9$ it moved faster than haemoglobin $\mathrm{K}$ but more slowly than haemoglobin $N$. In a family study this haemoglobin $J$ was found in three generations, and it was inherited as a Mendelian codominant character (Fig. 1). The haematological. examination of the father of the propositus, who also was a haemoglobin J trait carrier, gave normal haematological results. Haemoglobin 14.2 g. $/ 100 \mathrm{ml}$; red cells $4,900,000 / \mathrm{cu}$. mm.; packed cell volume $41 \%$; M.C.V. 84 cu. $-\mu$; M.C.H. $31 \mu \mu \mathrm{g}$. ; M.C.H.C. $35 \%$. No target cells or any other abnormal red cells were seen in the peripheral blood smear. Thus this haemoglobin variant by itself does not cause anaemia, and the cause of. the anaemia in the propositus remains to be determined.

* University Department of Immunology, Faculty of Medicine, Teheran. † Medical Research Council Abnormal Haemoglobin Research Unit, University Department of Biochemistry, Cambridge.

$\ddagger$ Holder of a World Health Organization Trainee Fellowship.

\section{Chemical Investigation of Haemoglobin J Iran}

Haemoglobin solutions were prepared and electrophoresis was carried out on paper, cellulose acetate, starch gel, and in starch block by the usual methods. On all occasions it was noted that haemoglobin $A$ and haemoglobin $\mathrm{J}$ were present in about equal quantity (Fig. 2). Haemoglobin A consists of two $\alpha$ and two polypeptide chains, and its formula can be written $\alpha_{2} \beta_{2}$. Haemoglobin $\mathrm{J}$ moves faster than haemoglobin $A$ towards the
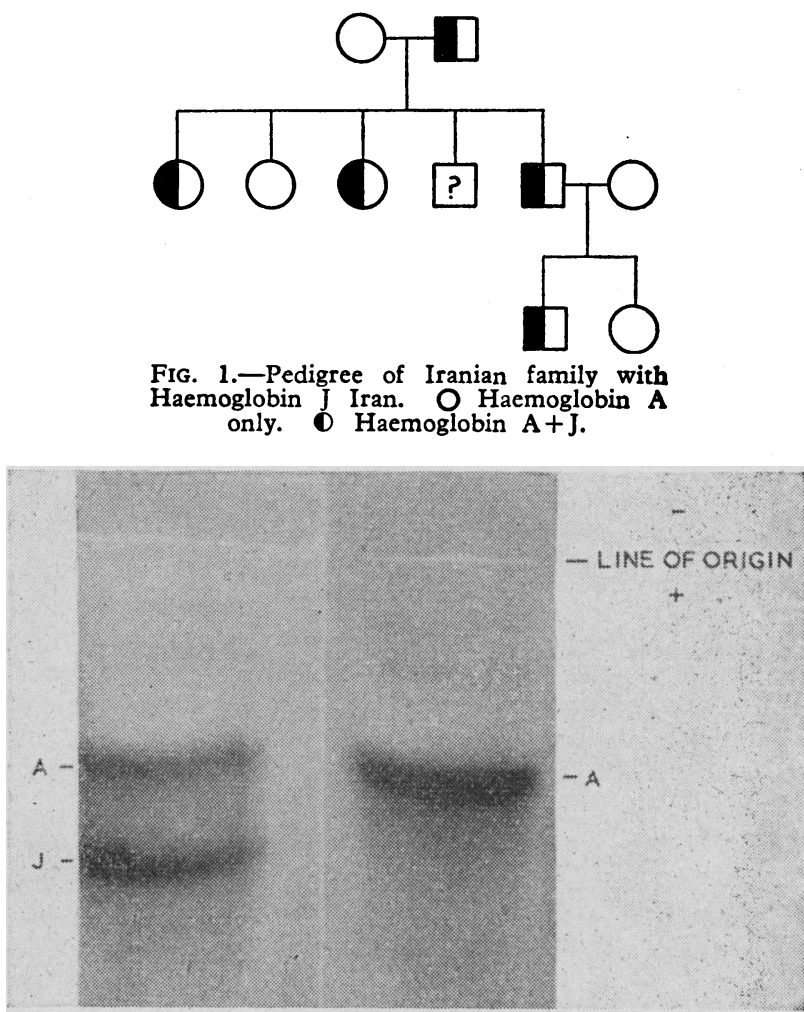

FIG. 2.-Starch-gel electrophoresis of the haemoglobin of the propositus (left) and a Haemoglobin A control. Haemoglobins A and $J$ are present in equal quantity in this haemoglobin of the 